\title{
Estudo experimental da influência da altura do enxerto ósseo intersomático na estabilidade da fixação monossegmentar anterior da coluna cervical ${ }^{*}$
}

\author{
Experimental study of the impact of intersomatic \\ bone graft height on the stability of anterior \\ monosegmental fixation of the cervical spine
}

Jorge Alfredo léo ${ }^{1}$, Antonio Carlos Shimano ${ }^{2}$, Gilberto de Araújo Pereira ${ }^{3}$, Helton luiz Aparecido Defino ${ }^{4}$

\section{RESUMO}

Objetivo: Estudar experimentalmente a influência da altura do enxerto ósseo intersomático da coluna cervical na estabilidade mecânica da fixação cervical anterior. Métodos: Foram realizados ensaios mecâni-

* Trabalho realizado no Laboratório de Bioengenharia do Departamento de Biomecânica, Medicina e Reabilitação da Faculdade de Medicina de Ribeirão Preto da Universidade de São Paulo - USP - Ribeirão Preto (SP), Brasil.

1. Pós-graduando do Departamento de Biomecânica, Medicina e Reabilitação do Aparelho Locomotor da Faculdade de Medicina de Ribeirão Preto - Universidade de São Paulo Faculdade de Medicina de Ribeirão Preto da Universidade de São Paulo - USP Ribeirão Preto (SP), Brasil.

2. Doutor, Professor do Departamento de Biomecânica, Medicina e Reabilitação do Aparelho Locomotor da Faculdade de Medicina de Ribeirão Preto - Universidade de São Paulo Faculdade de Medicina de Ribeirão Preto da Universidade de São Paulo - USP - Ribeirão Preto (SP), Brasil.

3. Doutor, Professor do Departamento de Bioestatística da Universidade Federal do Triângulo Mineiro - Uberaba (MG), Brasil.

4. Professor Titular do Departamento de Biomecânica, Medicina e Reabilitação do Aparelho Locomotor da Faculdade de Medicina de Ribeirão Preto - Universidade de São Paulo Faculdade de Medicina de Ribeirão Preto da Universidade de São Paulo - USP - Ribeirão Preto (SP), Brasil.

Endereço para correspondência: Helton L.A. Defino, Hospital das Clínicas de Ribeirão Preto, Departamento de Biomecânica, Medicina e Reabilitação do Aparelho Locomotor, Av. Bandeirantes, 3.900, Monte Alegre - 14048-900 - Ribeirão Preto (SP), Brasil. Tels.: +5516-3633-7559/16-3633-0336. E-mail: hladefino@fmrp.usp.br Recebido em 12/2/08. Aprovado para publicação em 28/5/08. Copyright RBO2008 cos utilizando a coluna cervical de suínos (C3-C4). Foram formados três grupos experimentais compostos por 20 segmentos da coluna cervical (C3-C4), de acordo com o grau de instabilidade produzido e a fixação do segmento vertebral. Grupo I: retirada do disco intervertebral e colocação de enxerto intersomático. Grupo II: retirada do disco intervertebral, colocação de enxerto intersomático e fixação anterior com placa. Grupo III: retirada do disco intervertebral, secção dos ligamentos posteriores e cápsulas articulares bilateralmente, colocação do enxerto intersomático e fixação anterior com placa. Cada grupo experimental foi dividido em dois subgrupos, de acordo com a altura do enxerto ósseo utilizado $(3,0 \mathrm{~mm}$ ou $6,0 \mathrm{~mm}$ ). Os segmentos vertebrais foram submetidos a ensaios mecânicos de flexão, flexão lateral e torção em máquina universal de ensaio. Os parâmetros analisados foram força máxima $(\mathrm{N})$ e o momento $(\mathrm{Nm})$ para produzir uma deflexão preestabelecida. Resultados: Não foi observada em todos os grupos experimentais diferença estatística dos valores da força máxima $(\mathrm{N})$ e do momento $(\mathrm{Nm})$, entre as diferentes alturas $(3,0 \mathrm{~mm}$ e $6,0 \mathrm{~mm})$ do enxerto ósseo intersomático. Conclusões: A estabilidade mecânica imediata da artrodese cervical monossegmentar anterior não sofreu influência da altura do enxerto ósseo intersomático nos ensaios de flexão, flexão lateral e torção.

Descritores - Coluna vertebral/cirurgia; Transplante ósseo; Biomecânica; Fusão vertebral/métodos; Vértebras cervicais/cirurgia; Suínos 


\section{ABSTRACT}

Objective: To perform an experimental study of the impact of intersomatic bone graft height of the cervical spine on the mechanical stability of anterior cervical fixation. Methods: Mechanical assays were performed using swine cervical spine (C3-C4). Three experimental groups were formed with 20 cervical spine segments (C3-C4) according to the degree of stability achieved and the fixation of the vertebral segment. Group I: removal of the intervertebral disc and placement of intersomatic graft. Group II: removal of the intervertebral disc, placement of the intersomatic graft, and anterior fixation with plate. Group III: removal of the intervertebral disc, bilateral section of posterior ligaments and joint capsules, placement of intersomatic graft, and anterior fixation with plate. Each experimental group was divided into two subgroups, according to the height of the bone graft used $(3.0 \mathrm{~mm}$ or $6.0 \mathrm{~mm})$. Vertebral segments were submitted to mechanical assays of flexion, lateral flexion, and torsion in a universal assay machine. The parameters analyzed were maximum strength $(N)$ and the time $(\mathrm{Nm})$ to produce a predetermined deflection. Results: Considering all experimental groups, the authors did not observe a statistical difference among the maximum strength $(N)$ and time $(\mathrm{Nm})$ between the different heights $(3.0 \mathrm{~mm}$ and $6.0 \mathrm{~mm})$ of the intersomatic bone graft. Conclusions: Immediate mechanical stability of anterior monosegmental cervical arthrodesis was not impacted by the intersomatic graft height in the flexion, lateral flexion, and torsion assays.

Keywords - Spine/surgery; Bone transplantation; Biomechanics; Spinal fusion/methods; Cervical vertebrae/surgery; Swine

\section{INTRODUÇÃO}

A artrodese cervical anterior por meio da discectomia e enxerto ósseo intersomático oriundo do ilíaco foi inicialmente proposta para o tratamento das doenças degenerativas da coluna cervical ${ }^{(1-2)}$; após o desen- volvimento das placas para a fixação anterior da coluna cervical, passou a ser também utilizada para o tratamento das lesões traumáticas discoligamentares que não apresentam considerável comprometimento do corpo vertebral (luxações uni e bifacetárias) ${ }^{(3-6)}$.

O enxerto ósseo desempenha papel biológico osteoindutivo e osteocondutivo na consolidação da artrodese e também participa na estabilidade mecânica ${ }^{(7-9)}$. O enxerto ósseo restaura a capacidade de suporte da carga pela coluna anterior e restaura a lordose fisiológica por meio da sua forma em cunha ${ }^{(10-11)}$.

$\mathrm{Na}$ constelação dos vários parâmetros que podem influenciar a estabilidade da artrodese cervical monosegmentar anterior ${ }^{(12-13)}$, tem sido destacada a forma e a altura do enxerto ósseo ${ }^{(14-16)}$. A utilização do enxerto ósseo intersomático de forma trapezoidal e com altura excessiva pode ocasionar o afastamento das facetas articulares posteriores durante a aplicação de forças axiais de compressão, que na presença de lesão ligamentar posterior aumenta a instabilidade do segmento vertebral lesado ${ }^{(17)}$.

Considerando a participação da altura do enxerto ósseo intersomático na estabilização da coluna cervical e levando em conta que a utilização de enxerto ósseo com altura superior à ideal poderia conduzir à instabilidade do segmento cervical, procuramos, por meio de ensaios mecânicos, avaliar a influência da altura do enxerto ósseo intersomático na estabilidade mecânica da artrodese cervical monossegmentar anterior, com o objetivo de identificar a altura adequada do enxerto ósseo capaz de conferir maior estabilidade à artrodese. A utilização do enxerto ósseo de altura superior à ideal pode induzir a instabilidade do segmento cervical.

\section{MÉTODOS}

Foram utilizados no estudo 60 segmentos de coluna cervical de suínos da raça Landrace, com cinco meses de idade e massa variando de 80 a 90kg. Os espécimes foram obtidos em abatedouro de animais. Os animais não foram sacrificados especificamente para a realização do estudo. O segmento vertebral C3 e C4 foi selecionado para o estudo. Para a padronização das dimensões das vértebras, foram utilizadas vértebras com altura entre 48 e $57 \mathrm{~mm}$ e largura entre 36 e $44 \mathrm{~mm}$. 


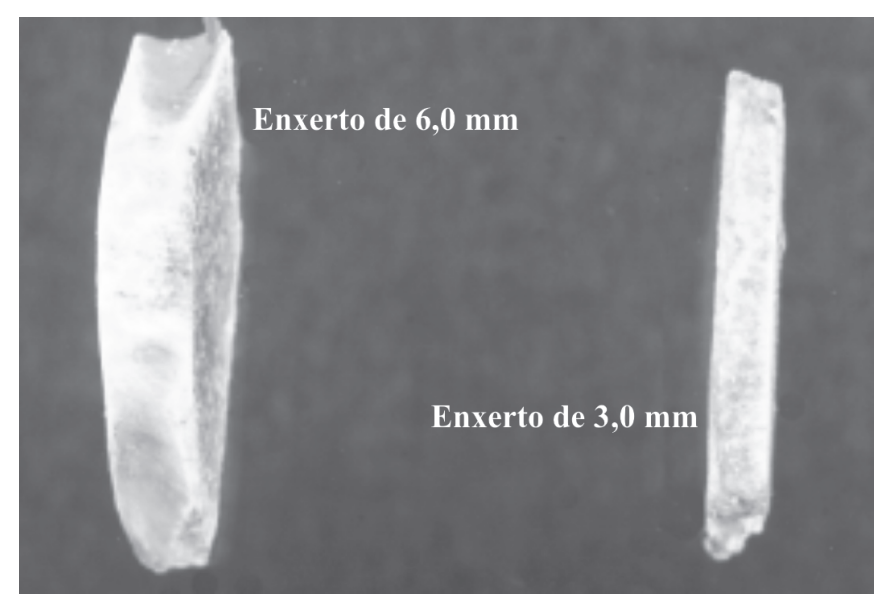

Figura 1 - Enxertos ósseos intersomáticos de 6,0mm e 3,0mm

Após a seleção e preparação, as vértebras eram acondicionadas em saco plástico e congeladas à temperatura de $-10^{\circ} \mathrm{C}$. A musculatura posterior da coluna cervical foi removida e os ligamentos posteriores (ligamento supra a interespinhoso) e as facetas articulares eram preservados. Somente o segmento vertebral C3C4 foi utilizado para o estudo. No dia anterior aos ensaios mecânicos, os segmentos vertebrais eram mantidos sob refrigeração e descongelados.

Foram formados três grupos experimentais de acordo com a extensão da lesão ligamentar e fixação do segmento vertebral. No grupo I, o disco intervertebral era removido e colocado enxerto ósseo intersomático. No grupo II, o disco intervertebral era removido, inserido o enxerto ósseo intersomático e o segmento vertebral fixado anteriormente com placa do tipo $\mathrm{H}$. No grupo III, o disco intervertebral era removido, os ligamentos posteriores e as cápsulas articulares bilateralmente eram seccionados e o segmento vertebral fixado com placa tipo H. Cada grupo experimental era formado por 20 segmentos da coluna cervical C3-C4. Em todos os segmentos $\mathrm{C} 3-\mathrm{C} 4$, foi utilizado enxerto ósseo intersomático. Na metade do grupo experimental, era utilizado enxerto ósseo intersomático de $3,0 \mathrm{~mm}$ de altura; enxerto ósseo intersomático de $6,0 \mathrm{~mm}$ de altura, na outra metade do grupo experimental, para a comparação dos resultados em função da altura do enxerto ósseo utilizado.

O enxerto ósseo foi confeccionado a partir do corpo vertebral dos segmentos cervicais não utilizados no

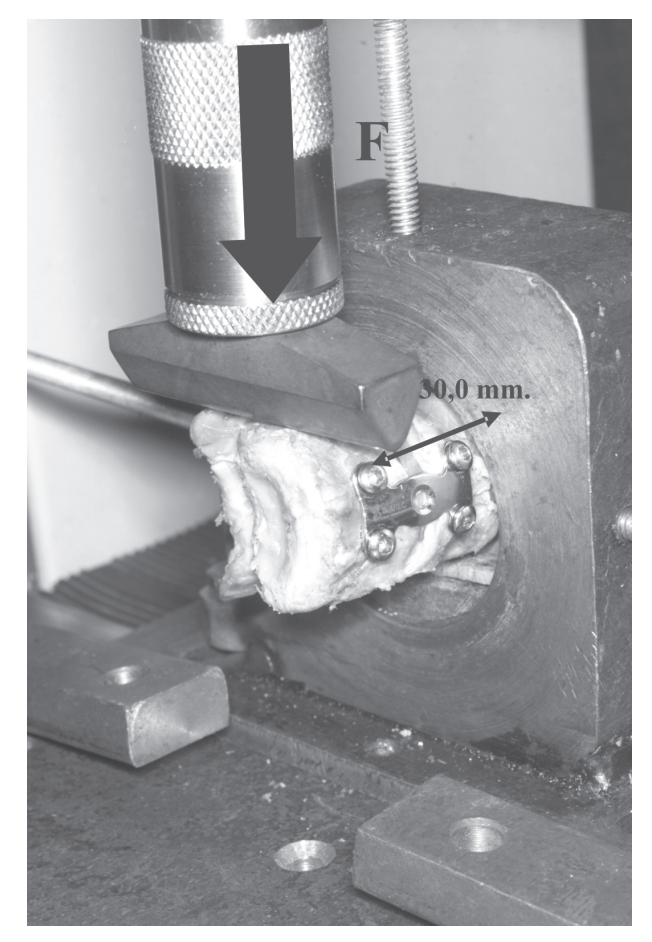

Figura 2

Posicionamento

do modelo experimental no ensaio de flexão lateral

estudo; possuía forma elíptica e $25,0 \mathrm{~mm}$ de comprimento, $15,0 \mathrm{~mm}$ de largura e $3,0 \mathrm{~mm}$ ou $6,0 \mathrm{~mm}$ de altura (figura 1).

A estabilização dos segmentos vertebrais foi realizada por meio de placas do "tipo H" de aço inoxidável e $28,0 \mathrm{~mm}$ de comprimento, fixadas por quatro parafusos do tipo cortical com $14,0 \mathrm{~mm}$ de comprimento e $3,5 \mathrm{~mm}$ de diâmetro. Foi confeccionado um guia para a padronização do orifício-piloto, que possuía inclinação concêntrica de $20^{\circ}$ em relação ao corpo vertebral. O torque de inserção dos parafusos foi padronizado em $0,4 \mathrm{~N}$ e os parafusos inseridos com o auxílio de torquímetro.

Foram realizados ensaios mecânicos de flexão, flexão lateral e torção para a observação da possível influência da altura do enxerto ósseo intersomático nas diferentes situações de instabilidade fixadas por meio da placa anterior associada ao enxerto ósseo (figura 2). As propriedades mecânicas analisadas foram força máxima $(\mathrm{N})$ e o momento $(\mathrm{Nm})$ para a obtenção de uma deflexão preestabelecida.

Os ensaios mecânicos foram realizados no Laboratório de Bioengenharia do Departamento de Biomecânica, Medicina e Reabilitação da Faculdade de Me- 


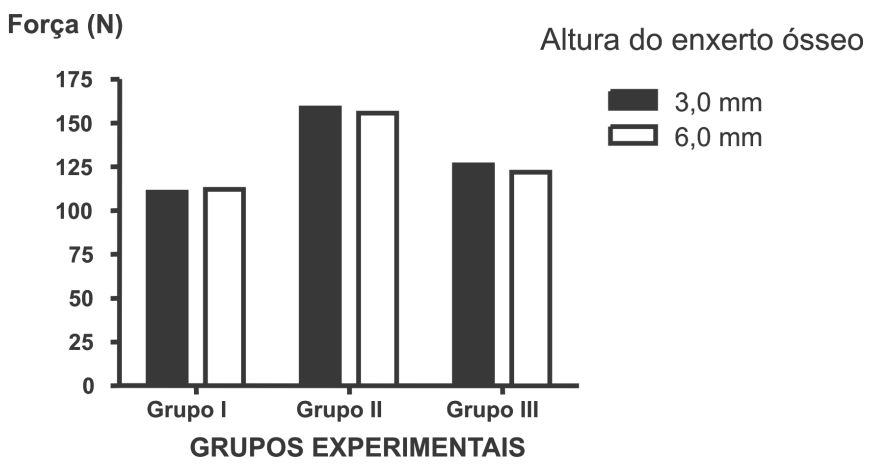

Figura 3 - Média dos valores da força máxima observada nos três grupos experimentais nos ensaios de flexão

dicina de Ribeirão Preto, utilizando máquina universal de ensaio mecânico $\left(\right.$ EMIC $\left.^{\circledR}\right)$ e os resultados registrados por microcomputador, através do software Tesc $V$ 1.13. Este programa confeccionava os gráficos da deflexão (mm) em função da força aplicada $(\mathrm{N})$. Nos ensaios de flexão e flexão lateral, foi utilizada a précarga de $10 \mathrm{~N}$ e velocidade de aplicação de carga de $5,0 \mathrm{~mm} / \mathrm{min}$. Nos ensaios de torção foi utilizada a précarga de $50 \mathrm{~N}$ e a velocidade de aplicação de carga de $5,0 \mathrm{~mm} / \mathrm{min}$.

A partir dos dados da deflexão em função da força aplicada, foi calculada a força máxima (N) e o momento $(\mathrm{Nm})$ para a deflexão $(\mathrm{mm})$ pré-definida. Para os ensaios de flexão, a deflexão máxima definida foi de 4,0mm, 3,0mm para os ensaios de flexão lateral e 6,5mm para os ensaios de torção.

A análise estatística foi realizada por meio dos testes de Kolmogorov-Smirnov, Lilliefors e Shapiro-Wilkings para a avaliação da normalidade da amostra. A comparação entre os valores da força máxima $(\mathrm{N})$ e momento $(\mathrm{Nm})$ nos grupos experimentais foi realizada por meio do teste $t$ de Student. O nível de significância considerado para os testes estatísticos utilizados foi de $5 \%(\alpha=5 \%)$.

\section{RESULTADOS}

Os resultados estão apresentados de acordo com a modalidade do ensaio mecânico realizado (flexão, flexão lateral e torção).

Ensaios de flexão - Os resultados dos ensaios de flexão estão ilustrados nas figuras 3 e 4 . No grupo I

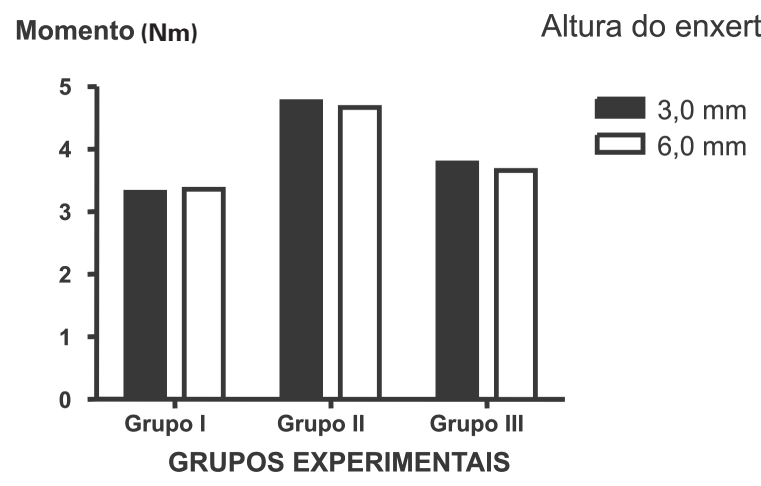

Figura 4 - Média dos valores do momento observado nos três grupos experimentais nos ensaios de flexão

(retirada do disco intervertebral e colocação de enxerto ósseo sem fixação com placa), a média da força máxima para o subgrupo do enxerto ósseo de 3,0mm foi de $110,48 \mathrm{~N} \pm 22,94 \mathrm{~N}$; para o subgrupo do enxerto ósseo de $6,0 \mathrm{~mm}$, foi de $112,03 \mathrm{~N} \pm 21,42 \mathrm{~N}(\mathrm{p}=0,8595)$. No grupo II (retirada do disco intervertebral e fixação com placa), a média da força máxima para o subgrupo do enxerto ósseo de $3,0 \mathrm{~mm}$ foi de $158,66 \mathrm{~N} \pm 58,34 \mathrm{~N}$; para o subgrupo do enxerto ósseo de $6,0 \mathrm{~mm}$, foi de $155,54 \mathrm{~N} \pm 60,36 \mathrm{~N}$ ( $\mathrm{p}=0,8522$ ). No grupo III (retirada do disco intervertebral e ligamentos posteriores e fixação com placa), a média da força máxima para o subgrupo do enxerto ósseo de 3,0mm foi de $126,10 \mathrm{~N}$ $\pm 31,74 \mathrm{~N}$; para o subgrupo do enxerto ósseo de $6,0 \mathrm{~mm}$, foi de $121,81 \mathrm{~N} \pm 23,37 \mathrm{~N}$ ( $\mathrm{p}=0,8453$ ).

No grupo I, a média do momento fletor no subgrupo do enxerto ósseo de $3,0 \mathrm{~mm}$ foi de $3,31 \mathrm{Nm} \pm 0,69 \mathrm{Nm}$; no subgrupo do enxerto ósseo de $6,0 \mathrm{~mm}$, foi de $3,36 \mathrm{Nm}$ $\pm 0,64 \mathrm{Nm}(\mathrm{p}=0,8595)$. No grupo II, a média do momento fletor no subgrupo do enxerto ósseo de 3,0mm foi de $4,76 \mathrm{Nm} \pm 1,75 \mathrm{Nm}$; no subgrupo do enxerto ósseo de $6,0 \mathrm{~mm}$, foi de $4,67 \mathrm{Nm} \pm 1,81 \mathrm{Nm}$ ( $\mathrm{p}=0,8522)$. No grupo III a média dos valores do momento fletor no subgrupo do enxerto ósseo de $3,0 \mathrm{~mm}$ foi de $3,78 \mathrm{Nm}$ $\pm 0,95 \mathrm{Nm}$; no subgrupo do enxerto ósseo de $6,0 \mathrm{~mm}$, foi de $3,66 \mathrm{Nm} \pm 0,70 \mathrm{Nm}(\mathrm{p}=0,8453)$.

Nos ensaios de flexão os resultados da força máxima e do momento fletor não apresentaram diferença estatística nos três grupos experimentais, considerando-se a diferença de altura do enxerto intersomático (3mm e $6 \mathrm{~mm})$ utilizado. 


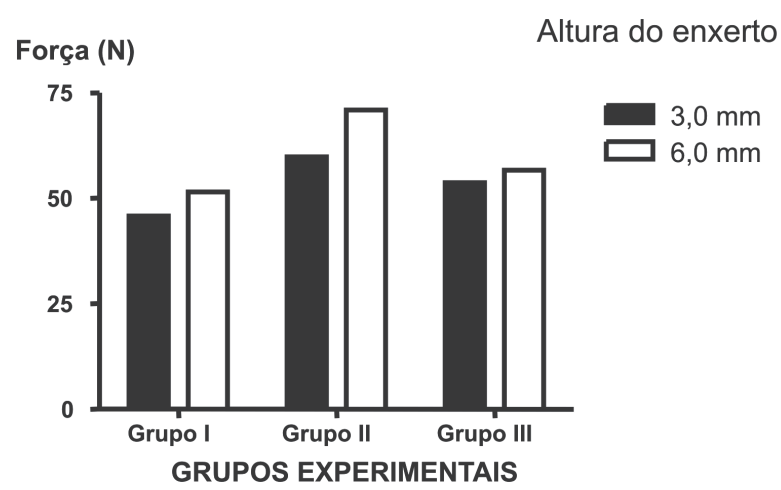

Figura 5 - Média dos valores da força máxima observada nos três grupos experimentais nos ensaios de flexão lateral

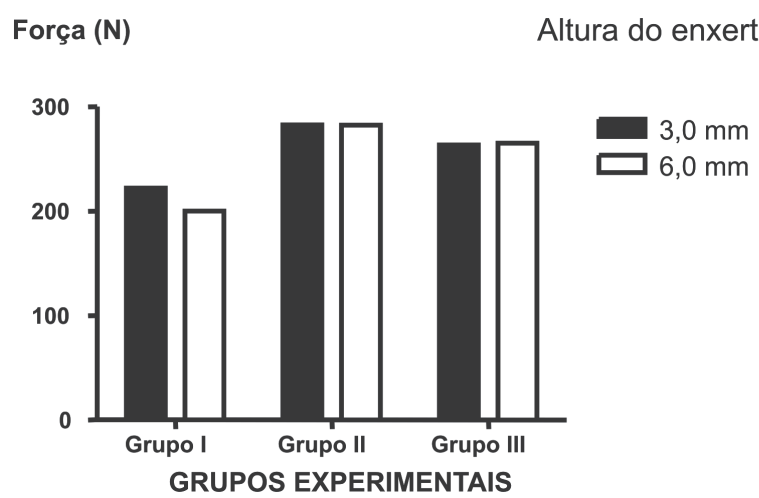

Figura 7 - Média dos valores da força máxima observada nos três grupos experimentais nos ensaios de torção

Ensaios de flexão lateral - Os resultados dos ensaios de flexão lateral estão ilustrados nas figuras 5 e 6. No grupo I, a média dos valores da força máxima no subgrupo do enxerto ósseo de $3,0 \mathrm{~mm}$ foi de $45,75 \mathrm{~N}$ $\pm 10,54 \mathrm{~N}$; no subgrupo do enxerto ósseo de $6,0 \mathrm{~mm}$, foi de $51,44 \mathrm{~N} \pm 12,83 \mathrm{~N}$ ( $\mathrm{p}=0,3081)$. No grupo II, a média dos valores da força máxima para o subgrupo do enxerto ósseo de $3,0 \mathrm{~mm}$ foi de $59,83 \mathrm{~N} \pm 5,75 \mathrm{~N}$; no subgrupo do enxerto ósseo de $6,0 \mathrm{~mm}$, foi de $70,93 \mathrm{~N} \pm$ $7,70 \mathrm{~N}$ ( $\mathrm{p}=0,2341$ ). No grupo III, a média dos valores da força máxima para o subgrupo do enxerto ósseo de $3,0 \mathrm{~mm}$ foi de $53,69 \mathrm{~N} \pm 8,26 \mathrm{~N}$; para o subgrupo do enxerto ósseo de $6,0 \mathrm{~mm}$, foi de $56,68 \mathrm{~N} \pm 5,01 \mathrm{~N}$ ( $\mathrm{p}=$ 0,2819).

No grupo I, a média dos valores do momento fletor no subgrupo do enxerto ósseo de $3,0 \mathrm{~mm}$ foi de $1,37 \mathrm{Nm}$ $\pm 0,32 \mathrm{Nm}$; no subgrupo do enxerto ósseo de $6,0 \mathrm{~mm}$, foi de $1,54 \mathrm{Nm} \pm 0,38 \mathrm{Nm}$ ( $\mathrm{p}=0,3081)$. No grupo II, a média dos valores do momento fletor no subgrupo do

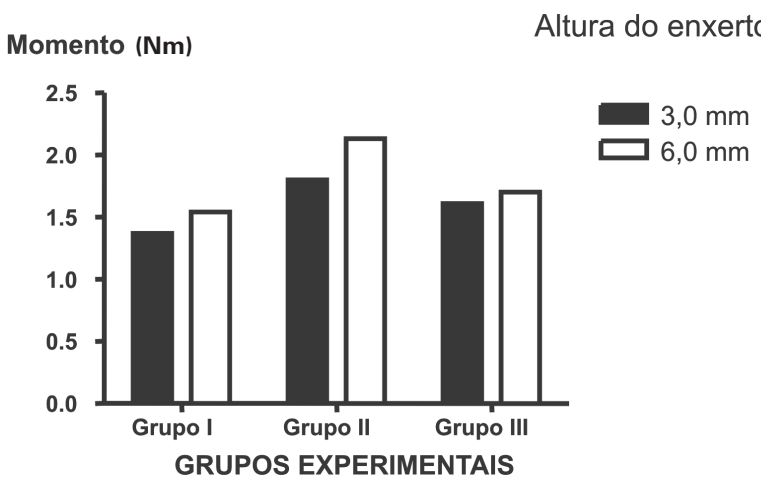

Figura 6 - Média dos valores do momento observado nos três grupos experimentais nos ensaios de flexão lateral

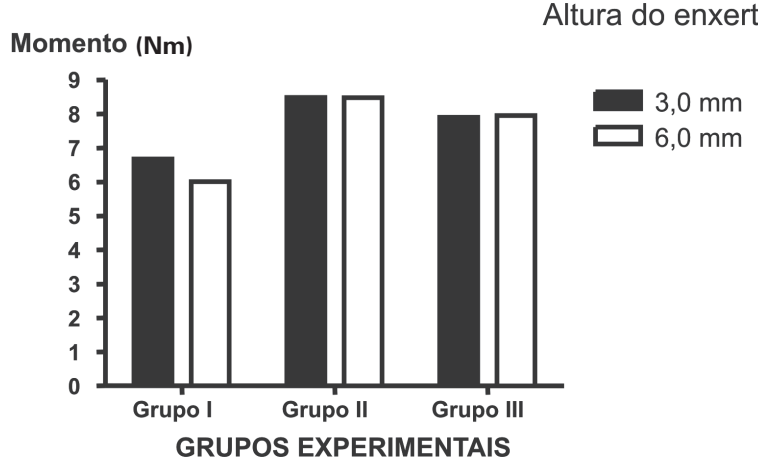

Figura 8 - Média dos valores do momento observado nos três grupos experimentais nos ensaios de torção

enxerto ósseo de $3,0 \mathrm{~mm}$ foi de $1,80 \mathrm{Nm} \pm 0,17 \mathrm{Nm}$; no subgrupo do enxerto ósseo de $6,0 \mathrm{~mm}$, foi de $2,13 \mathrm{Nm}$ $\pm 0,23 \mathrm{Nm}(\mathrm{p}=0,2341)$. No grupo III, a média dos valores do momento fletor no subgrupo do enxerto ósseo de $3,0 \mathrm{~mm}$ foi de $1,61 \mathrm{Nm} \pm 0,25 \mathrm{Nm}$; no subgrupo do enxerto ósseo de $6,0 \mathrm{~mm}$, foi de $1,70 \mathrm{Nm} \pm 0,15 \mathrm{Nm}$ $(\mathrm{p}=0,2819)$.

Nos ensaios de flexão lateral, os resultados da força máxima e do momento fletor não apresentaram diferença estatística nos três grupos experimentais, considerando-se a diferença de altura do enxerto intersomático (3mm e $6 \mathrm{~mm})$ utilizado.

Ensaios de torção - Os resultados dos ensaios de torção estão ilustrados nas figuras 7 e 8 . No grupo I, a média da força máxima para o subgrupo do enxerto ósseo de 3,0mm foi de 222,20N $\pm 49,16 \mathrm{~N}$; no subgrupo do enxerto ósseo de $6,0 \mathrm{~mm}$, foi de $200,15 \mathrm{~N} \pm$ $52,71 \mathrm{~N}(\mathrm{p}=0,3545)$. No grupo II, a média da força máxima para o subgrupo do enxerto ósseo de $3,0 \mathrm{~mm}$ 
foi de $282,70 \mathrm{~N} \pm 38,08 \mathrm{~N}$; no subgrupo do enxerto ósseo de $6,0 \mathrm{~mm}$, foi de $282,34 \mathrm{~N} \pm 61,62 \mathrm{~N}(\mathrm{p}=0,8631)$. No grupo III, a média da força máxima no subgrupo do enxerto ósseo de $3,0 \mathrm{~mm}$ foi de $263,42 \mathrm{~N} \pm 39,51 \mathrm{~N}$; no subgrupo de enxerto ósseo de $6,0 \mathrm{~mm}$, foi de $265,11 \mathrm{~N} \pm 51,87 \mathrm{~N}(\mathrm{p}=0,9888)$.

No grupo I, o valor da média do momento torsional no subgrupo do enxerto ósseo de $3,0 \mathrm{~mm}$ foi de $6,67 \mathrm{Nm}$ $\pm 1,47 \mathrm{Nm}$; no subgrupo do enxerto ósseo de $6,0 \mathrm{~mm}$, foi de $6,00 \mathrm{Nm} \pm 1,58 \mathrm{Nm}(\mathrm{p}=0,3545)$. No grupo II, o valor da média do momento torsional no subgrupo do enxerto ósseo de $3,0 \mathrm{~mm}$ foi de $8,48 \mathrm{Nm} \pm 1,14 \mathrm{Nm}$; no subgrupo do enxerto ósseo de $6,0 \mathrm{~mm}$, foi de $8,47 \mathrm{Nm}$ $\pm 1,85 \mathrm{Nm}(\mathrm{p}=0,8631)$. No grupo III, o valor da média do momento torsional no subgrupo do enxerto ósseo de $3,0 \mathrm{~mm}$ foi de $7,90 \mathrm{Nm} \pm 1,19 \mathrm{Nm}$; no subgrupo do enxerto ósseo de $6,0 \mathrm{~mm}$, foi de $7,95 \mathrm{Nm} \pm 1,56 \mathrm{Nm}$ ( $\mathrm{p}=0,9988)$.

Nos ensaios de torção, os resultados da força máxima e do momento torsional não apresentaram diferença estatística nos três grupos experimentais, considerando-se a diferença de altura do enxerto intersomático (3mm e $6 \mathrm{~mm})$ utilizado.

\section{DISCUSSÃO}

As propriedades biomecânicas da artrodese cervical monossegmentar anterior dependem de uma constelação de fatores: a densidade mineral do tecido ósseo, o tipo de fixação e o torque de inserção dos parafusos $^{(12-14)}$. A altura do disco intervertebral é outro desses fatores ${ }^{(15-16)}$.

Embora a artrodese cervical monossegmentar anterior seja o tratamento comum para a doença degenerativa (radiculopatia e mielopatia) e para as lesões traumáticas (luxação uni ou bifacetária) da coluna cervical, estas afecções devem ser consideradas como diferentes situações biomecânicas. O segmento vertebral é estável nas doenças degenerativas e instável nas lesões traumáticas.

O enxerto ósseo intersomático utilizado na artrodese cervical monossegmentar anterior tem a função de suporte da carga, restauração da lordose fisiológica do segmento vertebral e promoção da consolidação da ar- trodese do segmento vertebral por meio da osteoindução e osteocondução ${ }^{(17-18)}$. Pal et al demonstraram que $36 \%$ da carga axial aplicada sobre a coluna vertebral intacta é transmitida através dos corpos vertebrais ${ }^{(18)}$. A forma do enxerto ósseo é importante para restaurar a lordose fisiológica, que é obtida por meio da utilização do enxerto em forma de cunha ${ }^{(13)}$. Os enxertos com forma cilíndrica ou com grande altura promovem o afastamento e abertura das facetas articulares posteriores com a aplicação da compressão axial no segmento vertebral, que pode apresentar desvantagens na presença de lesão ligamentar posterior ${ }^{(16,19)}$.

A forma e a altura do enxerto ósseo intersomático da artrodese cervical monossegmentar anterior podem alterar a distribuição da carga, afetando a estabilidade biomecânica do segmento vertebral. Nesse sentido, a tendência da não consolidação foi observada quando a altura primária do disco intervertebral foi aumentada em mais do que $4 \mathrm{~mm}^{(15)}$. A altura excessiva do enxerto ósseo aumenta o risco da fratura do enxerto ou da placa vertebral terminal, o que pode resultar em afundamento do enxerto ${ }^{(15-16,20)}$. Por outro lado, a utilização de enxerto com pequena altura pode não restaurar a lordose cervical ${ }^{(16)}$.

Na prática, a altura dos enxertos ósseos intersomáticos tem sido definida de acordo com sua adaptação entre os corpos vertebrais durante o ato cirúrgico ou molde pré-operatório. A altura do enxerto ósseo intersomático recomendado na descrição original da técnica da artrodese cervical monossegmentar anterior era de 10 a $15 \mathrm{~mm}^{(2)}$; estudos mais recentes têm recomendado a altura de 4 a $7 \mathrm{~mm}^{(21)}$. No entanto, foi demonstrado experimentalmente que a altura pré-operatória do disco intervertebral não seria fator prognóstico preciso para a determinação da carga sobre o enxerto ósseo $^{(16,18)}$.

O trabalho que realizamos teve como objetivo principal a observação dos possíveis efeitos biomecânicos que a altura do enxerto intersomático poderia ocasionar na estabilidade biomecânica do segmento vertebral. Os três grupos experimentais foram confeccionados para simular as situações clínicas relacionadas com a não utilização da fixação e com a integridade ou lesão das estruturas ligamentares posteriores, que 
respectivamente ocorrem nas lesões degenerativas e traumáticas.

As dificuldades médico-legais da obtenção de colunas cervicais de humanos foi o motivo da escolha da coluna vertebral de suínos, material utilizado de modo satisfatório em outros experimentos ${ }^{(22-25)}$. O emprego do guia fixo para a perfuração dos quatro orifícios da placa eliminou a possível influência da angulação dos parafusos no corpo vertebral ${ }^{(26)}$. O torque de inserção foi padronizado em $0,4 \mathrm{Nm}$, valor que se encontra na faixa preconizada por Clausen et $a l^{(13)}$ e Grubb et $a l^{(27)}$. As alturas dos enxertos ósseos intersomáticos utilizados em nosso estudo (3,0 e 6,0mm) foram selecionadas com base nos valores de 4 a $5 \mathrm{~mm}$ estabelecidos por White $e t a l^{(21)}$. Aqueles representam valores abaixo e acima desse intervalo para teoricamente potencializar a possível influência da altura do enxerto ósseo sobre a estabilidade biomecânica. $\mathrm{O}$ modelo da placa de reduzida espessura e os parafusos não bloqueados $^{(14)}$ foram selecionados com o objetivo de potencializar a possível influência da altura do enxerto intersomático.

A altura do enxerto ósseo intersomático não interferiu na estabilidade mecânica do segmento vertebral,

\section{REFERÊNCIAS}

1. Bailey RW, Badgley CE. Stabilization of the cervical spine by anterior fusion. J Bone Joint Surg Am. 1960;42-A:565-94.

2. Smith GW, Robinson RA. The treatment of certain cervicalspine disorders by anterior removal of the intervertebral disc and interbody fusion. J Bone Joint Surg Am. 1958;40-A(3): 607-24.

3. Aebi M, Zuber K, Marchesi D. Treatment of cervical spine injuries with anterior plating. Indications, techniques, and results. Spine. 1991;16(3 Suppl):S38-45.

4. Cloward RB. Treatment of acute fractures and fracturedislocations of the cervical spine by vertebral-body fusion. A report of eleven cases. J Neurosurg. 1961;18:201-9.

5. de Oliveira JC. Anterior plate fixation of traumatic lesions of the lower cervical spine. Spine. 1987;12(4):324-9.

6. Ripa DR, Kowall MG, Meyer PR Jr, Rusin JJ. Series of ninetytwo traumatic cervical spine injuries stabilized with anterior ASIF plate fusion technique. Spine. 1991;16(3 Suppl):S46-55.

7. Anderson DG, Albert TJ. Bone grafting, implants, and plating options for anterior cervical fusions. Orthop Clin North Am. 2002;33(2):317-28. nos modelos experimentais que utilizamos. Foi possível observar, nos ensaios mecânicos, a tendência do segmento cervical, estabilizado com a placa anterior, tornar-se instável quando submetido à força de flexão, de acordo com os critérios biomecânicos ${ }^{(28)}$.

A altura ideal do enxerto ósseo intersomático utilizado nas artrodeses cervicais monossegmentares anterior permanece desconhecida e tem sido selecionada subjetivamente durante o ato cirúrgico com base na distração local realizada no segmento vertebral e a adaptação do enxerto ósseo no momento da cirurgia.

\section{CONCLUSÕES}

A estabilidade mecânica imediata da artrodese cervical monossegmentar anterior não sofreu influência da altura do enxerto ósseo intersomático nos ensaios de flexão, flexão lateral e torção, indicando que as alturas de $3,0 \mathrm{~mm}$ e $6,0 \mathrm{~mm}$ do enxerto ósseo não atuaram diversamente sobre a estabilidade mecânica imediata da fixação anterior da coluna cervical. Os resultados referentes a suínos não devem ser considerados como absolutamente iguais aos de ocorrência em humanos devido às diferenças entre as vértebras, destacando-se a densidade óssea.
8. Ryu SI, Lim JT, Kim SM, Paterno J, Willenberg R, Kim DH. Comparison of the biomechanical stability of dense cancellous allograft with tricortical iliac autograft and fibular allograft for cervical interbody fusion. Eur Spine J. 2006;15(9):1339-45. Erratum in: Eur Spine J. 2006;15(9):1346. Willenberg, Rafer [added].

9. Wang JL, Panjabi MM, Isomi T. The role of bone graft force in stabilizing the multilevel anterior cervical spine plate system. Spine. 2000;25(13):1649-54.

10. Dvorak MF, Pitzen T, Zhu Q, Gordon JD, Fisher CG, Oxland TR. Anterior cervical plate fixation: a biomechanical study to evaluate the effects of plate design, endplate preparation, and bone mineral density. Spine. 2005;30(3):294-301.

11. Ryken TC, Clausen JD, Traynelis VC, Goel VK. Biomechanical analysis of bone mineral density, insertion technique, screw torque, and holding strength of anterior cervical plate screws. J Neurosurg. 1995;83(2):325-9.

12. Wood EG 3rd, Hanley EN Jr. Types of anterior cervical grafts. Orthop Clin North Am. 1992;23(3):475-86.

13. Clausen JD, Ryken TC, Traynelis VC, Sawin PD, Dexter F, Goel VK. Biomechanical evaluation of Caspar and Cervical 
Spine Locking Plate systems in a cadaveric model. J Neurosurg. 1996;84(6):1039-45.

14. Smith SA, Lindsey RW, Doherty BJ, Alexander J, Dickson JH. An in-vitro biomechanical comparison of the Orosco and AO locking plates for anterior cervical spine fixation. J Spinal Disord. 1995;8(3):220-3.

15. An HS, Evanich CJ, Nowicki BH, Haughton VM. Ideal thickness of Smith-Robinson graft for anterior cervical fusion. A cadaveric study with computed tomographic correlation. Spine. 1993;18(14):2043-7.

16. Truumees E, Demetropoulos CK, Yang KH, Herkowitz HN. Effects of disc height and distractive forces on graft compression in an anterior cervical discectomy model. Spine. 2002;27(22):2441-5.

17. Anderson DG, Albert TJ. Bone grafting, implants, and plating options for anterior cervical fusions. Orthop Clin North Am. 2002;33(2):317-28.

18. Pal GP, Sherk HH. The vertical stability of the cervical spine. Spine. 1988;13(5):447-9.

19. Liu J, Ebraheim NA, Haman SP, Sanford CG Jr, Sairyo K, Faizan A, et al. How the increase of the cervical disc space height affects the facet joint: an anatomy study. Spine. 2006;31(12):E350-4.

20. Olsewski JM, Garvey TA, Schendel MJ. Biomechanical analysis of facet and graft loading in a Smith-Robinson type cervical spine model. Spine. 1994;19(22):2540-4.
21. White AA 3rd, Panjabi MM. Biomechanical considerations in the surgical management of cervical spondylotic myelopathy. Spine. 1988;13(7):856-60.

22. Callaghan JP, McGill SM. Frozen storage increases the ultimate compressive load of porcine vertebrae. J Orthop Res. 1995;13(5):809-12.

23. Lundin O, Ekström L, Hellström M, Holm S, Swärd L. Exposure of the porcine spine to mechanical compression: differences in injury pattern between adolescents and adults. Eur Spine J. 2000;9(6):466-71.

24. Oxland TR, Panjabi MM, Southern EP, Duranceau JS. An anatomic basis for spinal instability: a porcine trauma model. J Orthop Res. 1991;9(3):452-62.

25. Richman JD, Daniel TE, Anderson DD, Miller PL, Douglas RA. Biomechanical evaluation of cervical spine stabilization methods using a porcine model. Spine. 1995;20(20):2192-7.

26. Lowery GL, McDonough RF. The significance of hardware failure in anterior cervical plate fixation. Patients with 2- to 7 year follow-up. Spine. 1998;23(2):181-6; discussion 186-7.

27. Grubb MR, Currier BL, Shih JS, Bonin V, Grabowski JJ, Chao EY. Biomechanical evaluation of anterior cervical spine stabilization. Spine. 1998;23(8):886-92.

28. Ulrich C, Arand M, Nothwang J. Internal fixation on the lower cervical spine - biomechanics and clinical practice of procedures and implants. Eur Spine J. 2001;10(2):88-100. 